\title{
La Penitencia y sus formas Examen de su evolución histórica
}

No es mi intención penetrar en el campo estrictamente teológico. Durante la Semana varios teólogos han presentado sus eruditos y pensados estudios sobre estos puntos.

Las cuartillas siguientes persiguen una finalidad más humilde. Quisieran recordar algunos elementos aportados por la visión histórica resumida de la evolución de las formas penitenciales. Elementos que han de tenerse en cuenta en estos momentos, en los que, siguiendo las indicaciones del Concilio, se procede a un estudio reestructurativo del rito del sacramento de la penitencia. Datos históricos que, además, pueden ayudarnos también a precisar los elementos fundamentales que, como tales, han permanecido a lo largo de toda la evolución de las formas penitenciales.

Dentro de esta visión histórica de las formas penitenciales, no tomaremos en consideración aquellas formas que se limitaban a conceder el perdón de los llamados "peccata minora", o pecados no sometibles obligatoriamente a la penitencia antigua $\mathrm{u}$ oficial.

Tampoco es mi intención el precisar todos los elementos que hayan podido influir en esta evolución de las formas. Sencillamente me limitaré a indicar:

-que ha habido cambios y evolución en las formas penitenciales

- que esta evolución se ha hecho en medio de la oposición.

Ambos puntos irán entremezclados, con la finalidad de evitar repeticiones,

-y finalmente me interesa hacer notar que una -no digo la única- de las causas más influyentes en esta evolución lo ha constituido la que pudiéramos denominar (exigencias pastorales del pueblo cristiano». 
$\mathrm{Y}$ estos tres puntos los estudiaré limitando mi reflexión al paso de la penitencia antigua a la penitencia llamada (tarifada». Creo que podremos encontrar datos suficientes de reflexión muy instructivos para nuestra situación actual.

"La restauración o renovación de una institución, si no se adapta a la realidad suele concluir en un fracaso. Si queremos dar posibilidades de triunfo al proceso penitencial debemos adaptarle a los datos concretos de la vida cristiana de hoy, al cambio de acento en materia ética y a la distinta sensibilidad religiosa del hombre de hoy en relación con el hombre del pasado) "

Ha habido evolución en las formas penitenciales. $\mathrm{Ha}$ sido una evolución:

a) hacia la benignidad $y$

b) en medio de la discusión constructiva ${ }^{2}$.

\section{A La penitencia antigua}

Ya constituida la práctica penitencial antigua como algo institucionalizado y reglamentado nos encontramos con algunas mitigaciones dignas de tenerse en cuenta. Para valorar más justamente estas mitigaciones, a las que nos referimos, es conveniente recordar las características fundamentales de la penitencia antigua. Podríamos resumirlas así:

\section{Penitencia pública:}

Aunque no hemos de entender el adjetivo "pública) como una confesión oral pública de la falta, aún admitiendo que en algunos casos se diera ${ }^{3}$. Se refiere más bien a la publicidad que rodeaba al pro-

1. C. VOGEL, Le pécheur el la pénitence au Moyen-Age, París 1969,9

2. No sería dificil confeccionar una lista abundante de obras fundamentales sobre este tema. No obstante creo suficiente remitir al lector a la bibliografía que abundantemente señala B. POSCHMANN en casi todas sus obras y artículos, especialmente: La pénitence et onction des malades, París 1966; Poenitentia secunda, Bonn 1940; Dle abendländische KIrchenbusse im Ausgang des christlichen Altertums, München 1928; Die abendländlsche kirchenbusse Im frühęn Mittelaiter, Breslau 1930.

3. "De poenitentia scilicet quae a fidelibus postulatur, ne de singulorum peccatorum genere, libello scripta professio publice recitetur, cum reatus conscientiarum sufficiat solis sacerdotibus indicari confessione secreta. Quamvis enim plenitudo fidei videatur esse laudabilis, quae propter Dei timoren apud homines erubescere non veretur, tamen quia non omnium huiusmodi sunt peccata, ut ea, qui poenitentiam poscunt, non timeant publicare, removeatur tam improbabllis consuetudo, ne multis a poenitentiae remedis arceantur, dum aut erubescunt aut metuunt inimicis suis 
ceso penitencial a través de los diversos estadios de que se componía: entrada en el grupo de los penitentes, cumplimiento de la penitencia, reconciliación y readmisión en el seno de la comunidad. Todos ellos eran hechos visibles a cuantos participaban en los respectivos actos cúltico-litúrgicos. No obstante, aunque no hubiera una confesión pública oral, el simple hecho de formar parte de los penitentes era una indicación suficiente para pensar que se había incurrido en alguno de los graves pecados sometibles a la penitencia antigua.

\section{Penitencia dramática:}

Dramatismo proveniente fundamentalmente de la exclusión de la comunidad. La asamblea local, reunida en torno a su cabeza, el obispo rodeado de sus clérigos, al aceptar al pecador en su condición de penitente lo separaba de la comunidad, era expulsado de ella en mayor o menor grado, ya que existe discusión entre los historiadores, como signo de la situación espiritual en que el mismo pecador se había constituido por su obra pecaminosa : ajeno al pueblo de Dios, al misterio de la reconciliación de los hombres con Dios a través de Cristo. Exclusión que, sin embargo, no impedía a la comunidad hacer oración y penitencia por el pecador que labraba su conversión en medio de las prácticas penitenciales. Pero exclusión real y acompañada de tales consecuencias que permite a algunos historiadores afirmar que los penitentes eran cristianos capitidiminuidos de derechos.

\section{Penitencia laboriosa:}

El cristiano pecador y arrepentido, durante el tiempo penitencial debía ofrecer a Dios una reparación exigente, consistente en duras prácticas penitenciales - mientras permanecía en las filas de los penitentes-, y en la aceptación de las consecuencias postpenitenciales. Precisamente lo que los teólogos llamarán la reparación juega un papel importantísimo en la práctica penitencial de los primeros siglos.

\footnotetext{
sua facta reserari, quibus possint legum constitutione percelli. Sufficit enim illa confessio quae primum Deo offertur, tum etiam sacerdoti, qui pro delictis poenitentium preccator accedit. Tunc enim demum plures ad poenitentiam poterunt provocari, si populi auribus non publicetur conscientia confitentis".

S. LEON MAGNO, Ep. CLXVIII ad universos episcopos per Campaniam, Samnium et Picenum constitutos, PL. 54, 1211 A/B).

C. VOGEL, Le pécheur et la pénitence dans l'Eglise Ancienne, París 1966, 10-11; C. VOGEL, "Un problème pastoral au VI siècle. La poenitentia in extremis au temps de Césaire, évêque d'Arles": Parole de Dieu et Sacerdoce, París Tournai 1962, 125, not. 1; C. VOGEL, Le pécheur et la pénitence au Moyen-Age, París 1969, 17.
} 
Podríamos afirmar que ocupa el primer puesto entre todos los elementos penitenciales, en cuanto exteriorización de una conversión sincera y firme. La satisfacción penitencial era una especie de test de la veracidad de la conversión de los arrepentidos. La contrición se exteriorizaba, se alimentaba y se perfeccionaba concretamente en la dureza de estas prácticas penitenciales a que se les sometía. Dureza en cuanto a la intensidad y también en cuanto a la duración de las mismas. La Iglesia antigua consideraría escandaloso la reconciliación de un pecador antes de que hubiera dado pruebas suficientes - de este estilode su arrepentimiento y antes de que hubiera sido castigado convenientemente por su falta.

La predicación de $\mathrm{S}$. Cesáreo de Arlés es un testimonio clarísimo del grave problema que planteaba la ausencia de prácticas penitenciales en los moribundos. Se plantea agudamente el cómo proceder en la práctica con aquellos moribundos que

a) no han formado parte de las filas de los penitentes, ni

b) han practicado la penitencia individual durante su vida $y$, sin embargo,

c) a las puertas de la muerte, desean obtener el perdón de sus pecados y ser reconciliados con la comunidad eclesial ${ }^{4}$.

\section{Penitencia no iterable:}

Este punto no suscita la más mínima discusión entre los historiadores de la penitencia antigua, a pesar de las consecuencias que de él se deducen. Entre las razones que les llevan a esta conclusión : la comparación establecida entre el bautismo como penitencia primera, y este sacramento, como penitencia segunda; y la consideración de la recaída en los pecados sometibles a la penitencia antigua, como una prueba de la falta de verdadero arrepentimiento y de una sincera conversión ${ }^{5}$.

4. Al tratar de este tema, aunque brevemente, idicaremos la bibliografía correspondiente.

5. "De his vero non incongrue dilectio tua apostolicam sedem credidit consulendam, qui acta poenitentia, tanquam canes et sues ad vomitos pristinos et volutabra redeuntes, et militiae cingulum, et ludicras voluptates, et nova coniugia, et inhibitos denuo appetivere concubitus; quorum professam incontinentiam generati post absolutionem filii prodiderunt. De quibus quia iam non habent suffugium poenitendi, id duximus decernemdum, ut sola intra Ecclesiam fidelibus oratione iungantur, sacrae mysteriorum celebritati, quamvis non mereantur, intersint; a Dominicae autem mensae convivio segregentur: ut hac saltem districtione correpti, et ipsi in se sua errata castigent. et aliis exemplum tribuant, quatenus ab obscenis cupiditatibus abstrahantur. Quos tamen, quoniam carnali fragilitate ceciderunt viatico munere, cum ad Dominum coeperint proficisci, per communionis gratiam solumus sublevari. Quam formam et circa mulieres quae se post poenitentiam talibus 
El principio de la no iterabilidad se ha aplicado con el más estricto rigor hasta la entrada de la penitencia tarifada. Los demás elementos integrantes de la práctica penitencial de los primeros siglos nos ofrecen ciertas mitigaciones, pero en éste de la no iterabilidad de la penitencia no constatamos mitigación alguna. Los Padres de la Iglesia escucharán las voces, a veces agudas, que se alzaban contra la so iterabilidad, pero no se atrevieron a poner en duda dicho principio.

\section{Penitencia finalmente excepcional:}

Un adjetivo que quizás pudiera entenderse en doble sentido

a) excepcional, primeramente, porque, dada la dureza de la mis$\mathrm{ma}$, serían pocos los pecados que debían someterse a ella, aunque no intentemos limitarlos a tres: adulterio, homicidio y apostasía y sin olvidar tampoco que, a partir del siglo III hasta el VI, se incrementa considerablemente el número de pecados sometibles a la penitencia.

b) Y excepcional, en segundo término, porque, aún habiendo incurrido en alguna de las faltas sometibles a la penitencia, eran pocos los que se sentían internamente invitados y suficientemente fuertes para practicar la penitencia en su forma oficial. Eran varias las razones que los disuadían de presentarse como candidatos de tales prácticas:

r) en un principio el enrolarse en las filas penitenciales oficiales era colorarse con una reputación nada envidiable.

2) no es difícil comprender que las características indicadas en las líneas anteriores contribuían, unas más y otras menos, a conterir ese cariz de excepcional a la penitencia antigua. Ciertamente debían de pesarles considerablemente las duras prácticas penitenciales del período que permanecían entre los penitentes, pero la no iterabilidad ocupaba el primer lugar de influjo

pollutionibus devinxerunt, servandam esse censemus". (Epistola decretalis Siricii papae ad Himerium Tarraconense episcopum sub titulis XVI, PL. 56,557 A/B.

"Hucusque, Christe Domine, de poenitentiae disciplina servis tuis dicere vel audire contingat, quousque tiema delinquere non oportet audientibus: del nihil iam de poenitentia noverint, nihil eius requirant. Piget secundae, imo lam ultimae spei subtexere mentionem, ne retractantes de resideuo auxilio poenitendi, spatium adhuc delinquendi demonstrare videamur". QUINTI SEPTIMI FLORENTIS TERTULIANI, De poenitentia liber c. VII. PL. 1. 1240). "Nam si veram agerent poenitentiam, iterandam postea non putarent: quia sicut unum baptisma, ita una poenitentia, quae tamen publice agitur; nam quotidie nos debet poenitere peccati: sed haec delictorum leviorum, illa graviorum"

(S. AMBROSSI MEDIOLANENSIS EPISCOPI, De poenitentia libri duo II, c. X, PL. 16,520)

A. BOUDINHON. "Sur I'histoire de la pénitence. A propos d'un ouvrage récent": Revue d'Histoire et de Littérature Relıgieuse 2 (1897) 323; C. VOGEL, "Un problème pastoral au V1 siêcle..." Parole de Dieu et Sacerdoce, p. 126. 
negativo. $\mathrm{Y}$ es comprensible en medio de un ambiente dominado por el pensamiento escatológico. El hecho de que la penitencia no fuera iterable, unido al de la propia debilidad que les hacía temer prudentemente una nueva recaída, invitaba poderosamente al aplazamiento de la práctica penitencial oficial hasta los últimos momentos de la vida. Así podían tener la seguridad de encontrarse en las condiciones convenientes, cuando llegara este momento.

3) Finalmente poseían una gran fuerza dilatoria las obligaciones con que se veía recargada la vida cristiana, de aquellos que ya habían practicado la penitencia oficial. Resumámosla brevemente :

-abstención de todo uso matrimonial, si estaban casados, o de contraerlo, si todavía no se habían casado ${ }^{6}$

-abstención de todo uso de las armas, aunque fuera en el ejército $^{7}$

-abstención de todo negocio ${ }^{8}$

- prohibición de recibir las órdenes sagradas, o excluidos de la penitencia oficial si ya las habían recibido ${ }^{9}$

6. De ahí la necesidad de obtener el consentimiento de la comparte antes de acudir a recibir la penitencia: "Poenitentiam coniugatis non nisi ex consensu dandam" (Concilium Arelatense II, c. 22, J. D. MANSI. Sacrosum Conciliorum nova et amplissima collectio, Akademische Druck U. Verlagsanstalt, Graz, VII, 881).

"Ut ne quis benedictionem poenitentia iuvenibus personis credere praesumat: certe coniugatis, nisi ex consensu partium, et aetate iam plena, cam dare non audeant" (Concilum Aurelianense III c. 24 , MANSI, o.c. IX, 18).

Prohibición de las segundas nupcias: "Poenitens quaecumque defuncto viro alii nubere praesumpserit vel suspecta, vel interdicta familiaritate cum extraneo vixerit, cum eodem ab ecclesiae liminibus arceatur. Hoc etiam de viro in poenitentia posito placuit observari" (Concilum Arelantense II, c. 21, MANSI, o.c. VII, 881).

7. "Si quis poenitentiae benedictione suscepta ad saecularem habitum militiamque reverti praesumpserit, viatico concesso, usque ad exitum exconmunicatione plectatur" (Concilium Aurellanense III c. 25, MANSI, O.c. IX, 18)

Concilium Andegavense c. 5, MANSI, o.c. VII, 901

"Contrarium est omnino ecclesiasticis regulis post poenitentiae actionem redire ad militíam saecularem, cum Apostolus dicat: Nemo militans Deo implicat se negotiis saecularibus... Unde non est liber a laqueis diaboli qui se militia mundana voluerit implicare" (S. LEON MAGNO, "Leo episcopus Rustico Narbonensi episcopo, inq. XII, PL., 54, 1206-1207).

8. Qualitas lucri negotiantem aut excusat aut arguit, quia est et honestus quaestus et turpis. Verumtamen poenitenti utilius est dispendia pati quam periculis negotiationis obstríngi, quia difficile est inter ementis vendentisque comercium non intervenire peccatum" (S. LEON MAGNO, Leo episcopus Rustico Narbonensi episcopo. Inq. XI. PL., 54, 1206).

"De his qui suscepta poenitentia religionem suae professionis obliti ad saecularia relabuntur, placuit eos et a communione suspendi et ab omnium catholicorum convivio separari. Quod si post interdictum cum eis quisquam praesumpserit manducare, et ipse communione privetur" (Concilium Aurellanense I. c. 11, MANSI, o. c. VIII, 353).

Concilium Epaonense c. 23, MANSI, o.c. VIII, 562.

9. “Illud quoque nos par fuit providere, ut sicut poenitentiam agere cuiquam non conceditur clericorum, ita et post poenitudinem ac reconciliationem nulli unquam laico liceat honorem clericatus adipisci; quia quamvis sit omnium peccatorum contagione mundati, nulla tamen debent gerendorum sacramentorum instrumenta suscipere, qui dudum fuerint vasa vitiorum". (Epistola decretalis Siricii papae ad Himerium Tarraccnensem episcopum sub titulis XVI, tit. XIV, PL. 56,561). 
-estaban excluidos de la penitencia oficial los jóvenes ${ }^{10}$ -irrepetible ${ }^{11}$

Es posible que esta forma de penitencia oficial respondiera a la situación de la Iglesia de los primerísimos tiempos. Se trataba de una Iglesia naciente, formada por elementos selectos y muy conscientes que vivían con intensidad su ideal y se encontraban prácticamente en una especie de gheto, al que les confina, en parte la sociedad, en que viven, y que en parte elegían y se creaban ellos mismos ${ }^{12}$. A medida que pasan los años, las conversiones van aumentando y los cristianos se integran progresivamente en la vida social. Entonces es cuando comienzan a sentirse las consecuencias dolorosas de estos principios penitenciales enunciados para unas circunstancias distintas de aquellas en las que vivía la Iglesia de las épocas posteriores. Pensando detenidamente estas consecuencias, llegaremos a la conclusión de que, si en principio todos los cristianos tenían abiertas las puertas de la penitencia oficial, en la práctica, sin embargo, la mayor parte se veían imposibilitados de celebrarla por la misma fuerza de las circunstancias.

Los pastores de almas viven el problema. Oyen y comprenden las voces de oposición contra tal forma de penitencia. El problema lo vive tanto la Iglesia Oriental como la Occidental. El problema es el mismo, pero la solución durante algunos siglos parece que ha sido distinta. En la decisión de la Iglesia Oriental ha podido influir el caso

\footnotetext{
"Alienum est a consuetudine ecclesiastica ut qui in presbyterali honore aut in diaconii gradu fuerint consecrati, ii pro crimine aliquo suo per manus impositionem remedium accipiant poenitendi: quod sine dubio ex apostolica traditione descendit, secundum quod scriptum est: Sacerdos si peccaverit, quis orabit pro illo. Unde huiusmodi lapsis, ad promerendam misericordiam Dei, privata est expetenda secessio, ubi illis satisfactio, si fuerit digna, sit etiam fructuosa" (Leo episcopus Rustico Narbonensi episcopo, Inq. II, PL. 54, 1203-1204) vid. comentario a este texto en C. VOGEL, La discipline pénitentielle en Gaule. Des origines a Ia fin du VII siècle, París 1952, 55). GENNADII MASSILIENSIS, De ecclesiasticis dogmatibus c. 72, PL. 58, 977; Statuta Ecclesiae ant.qua vid. H. T. BRUNS, Canones Apostolorum et conciliorum saeculorum IV, V, VI, VII, Berlín 1839 , vol. I, 147.

10. Concllium Aurelianense III, c. 24, MANSI, o.c. IX, 18 vid. nota 6; Concilio de Oriẹans (538) c. 24 vid. BRUNS, 0.c. II, 199;

Pero la juventud no sigue un criterio de edad, sino de vitalidad de las pasiones: Avitus viennensis episcopus. Victorio episcopo PL. 59, 234-235. Después se admitieron ciertas mitigaciones: "In adolescentia constitutus, si urgente aut metu mortis, aut captivitatis periculo, poenitentiam gessit et postea timens lapsum incontinentiae juvenilis, copulam uxoris elegit, ne crimen fornicationis incurreret, rem videtur fecisse venialem, si praeter coniugem, nullam omnino cognoverit. In quo tamen non regulam constituimus, sed quis sit tolerabilius aestimamus. Nam secumdum veram cognitionem nihil magis ei congruit qui poenitentiam gessit, quam castitas perseverans et mentis et corporis" (Leo episcopus Rustico Narbonensi episcopo. Inq. XIII, PL. 54, 1207)

11. Vid. nota 5. "Quamvis ergo caute salubriterque provisum sit ut locus illius humillimae poenitentiae semel in Ecclesia concedatur, ne medicina vilis minus esse aegrotis, quae tanto magis salubris est, quanto minus esset aegrotis, quae tanto magis salubris est, quanto minus contemptibilis fuerit". (S. AURELII AUGUSTINI, Epistolae 153, PL. 33, 656).

12. J. Lebreton - J. Zeiller. L'Eglise primitive (A. Fliche- V. Martín, Histolre de l'Eglise I) Paris 1946, 398-9; IBID. II, 429-438.
} 
planteado por el penitenciario de Costantinopla, unido a algunas otras circunstancias ambientales ${ }^{13}$. No podemos afirmarlo ni negarlo. Lo cierto es que la Iglesia Oriental se muestra más decidida y suprime la manera uniforme hasta entonces existente en ambas iglesias. Mientras tanto la Iglesia Occidental se muestra más remisa y sólo intenta ciertas mitigaciones, todas ellas conseguidas muy lentamente y en medio de oposiciones, que procuran salvar a todo precio el temible principio de la no iterabilidad de la penitencia oficial ${ }^{133^{\circ}}$.

-la professio religiosa

-la satisfactio secreta

-el agere poenitentiam, opuesto al accipere poenitentiam.

B La professio religiosa, o la vida religiosa como forma de obtener el perdón de los pecados

El pensamiento de que la vida religiosa fue un medio de obtener el perdón de los pecados es tan común, que ciertos textos - hoy definitivamente referidos a la (satisfactio secreta) - algunos historiadores los interpretaban como referidos a la vida religiosa ${ }^{14}$.

Los contemporáneos de aquellos tiempos se preguntaban si los religiosos debían practicar la penitencia, y caso de ser afirmativa la respuesta, cómo deberían practicarla. Responden sin titubeos que no deben someterse a la penitencia oficial, porque su misma vida religiosa constituye una práctica excepcional de la penitencia. Es una segunda renuncia que recuerda la del bautismo y que les permite, a pesar de sus pecados, recibir la comunión. Vienen a pensar que si los religiosos

13. A. BOUDINHON, "Sur l'histoire de la pénitence. A propos d'un ouvrage récent": Revue d'Histoire et Littérature Religieuse 2 (1897) 326.

13 a. "La tentative fait par Césaire d'Arles pour rendre accessible aux pécheurs la pénitence antique sous la forme de la paenitentia in extremis est la seule de ce genre sur laquelle nous renseignent les sources. Elle constitue un maximum de ce qu'un évêque de l'Église ancienne ait jamais osé entreprendre en matière pénitentille: aucun pasteur n'a jamais songé à reformer la structure de la pénitence antique en dérogeant, par exemple, au principé de la non rélterabillté ou en abolissant les interdits pénitentiels. Le grand évêque gallo-romain a essayé de résoudre, suivant ce qu'il croyait possible, le probléme créé par une institution inapplicable. II n'est pas interdit de penser qu'en insistant sur la valeur de l'expiation accomplie en dehors de l'ordo poenitentium, Césaire a indirectement préparé, sinon ouvert, la vole à la pénitence insulaire". (C. VOGEL. Un problème pastoral au $V_{1}$ sieccle. La paenitentia in extremis au temps de Césaire, évêque d'Arles": Parole de Dieu et Sacerdoce. París-Tournai 1962, 137).

14. GENNADII MASSILIENSIS, De eccleslasticis dogmatibus, c. 53, PL. 58, 994; E .AMANN "Pénitence": DTC. XII, 821, 878; E. GóLLER, "Studien über das gallische Busswesen zur Zeit Cäsarius von Arles und Gregors von Tours": Archiv für Kathollsches Kirchenrecht 109 (Mainz 1929) 20; B. POSCHMANN, Die abenlänđische Kirchenbusse im Ausgang des christllichen Altẹrtums, München 1928, 77, 130: J. TIXERONT, Histoire des dogmes III, 399 not. 3. Cfr. P. GALTIER, "Pénitents et convertis. De la pénitence latine à la pénitence celtique": Revue d'Histolre Ecclesiastique 33 (1937) 6-29, 277-305. 
no practican la penitencia oficial, no es porque se lo prohiba la iglesia; sino porque la forma oficial de penitencia es buena para los laicos cristianos, pero los religiosos tienen otra forma - su professio religiosaque es mejor todavía.

Es conveniente recordar sus características para acentuar su distinción de la (satisfactio secreta). Las resumimos en estas líneas: ledad

- es un alejamiento del mundo y, por tanto, una retirada a la so-

- se hace mediante un compromiso preciso y formal de servir a Dios. Media un pacto entre el pecador que, arrepentido, se retira a la vida religiosa y Dios. Y desde el día y el momento en que haga efectivo dicho pacto de renuncia al mundo y se comprometa a servir a Dios, quedan perdonados todos sus pecados. Por consiguiente el perdón de los pecados va unido directamente a la misma profesión religiosa. Esta se hacía mediante un compromiso escrito.

- parece la "professio religiosa» también lleva consigo la toma de un hábito especial, puesto que Casiano habla de que, para no ser reconocido como religioso, habría que dejar el hábito propio del religioso y tomar uno secular ${ }^{15}$.

\section{La (conversio» o (satisfactio secreta) como forma de obtener el perdón de los pecados.}

No ha sido fácil para los historiadores el precisarnos en qué consistía esta "satisfactio secreta) y el valor redentivo de los pecados que se le atribuyera. Se han exigido largos estudios y profundas reflexiones hasta llegar a dar consistencia a los "conversi" como un estado diferente tanto del estado u (ordo poenitentium) - aquellos que estaban practicando la forma oficial de penitencia - como del estado o (professio religiosa).

Esta dificultad de dar consistencia a los (conversi) como estado distinto provenía de que tanto los escritos conciliares como los escritos particulares utilizan el vocablo "conversi" para designar indistintamente :

\footnotetext{
15. P. GALITIER. "Pénitents et convertis. De la pénitence latine à la pénitence celtique": Revue d'Hlstoire Ecclesiastique 33 (1937) 5-29, 277-305.

C. VOGEL, La discipline pénitentielle en Gaule. Des origines a la fín du VII siècle", París $1932,132-133$.
} 
- a los aspirantes a la entrada en la vida religiosa o ya entrados en ella

- a los que estaban practicando la penitencia oficial en su primer estadio: (ordo poenitentium)

-a los propiamente (conversi).

Pero resulta que, durante mucho tiempo, los dos únicos estados adecuadamente identificados y con consistencia propia eran:

-el de los que practicaban la penitencia oficial

- el de los que aspiraban a entrar o ya habían entrado en la vida religiosa. Consiguientemente el estado de los (conversi) era identificado con uno de los dos anteriores, según el contexto. Típico texto sobre los conversi, pero que se atribuía a la vida religiosa, es el que se lee en Genadio en su Ecclesiastica Dogmata ${ }^{16}$.

Hoy creo que podamos dar ya como asentada la consistencia de la "satisfactio secreta" como estado con vida propia, independiente tanto del (ordo poenitentium" como de la "professio religiosa). Contamos con magníficos estudios que, por distintos caminos y completándose entre sí, prueban de forma terminante a mi modo de ver, la consistencia propia e independiente de la "satisfactio secreta). Estos estudios son debidos a Galtier ${ }^{17}$ y a Vogel ${ }^{18}$.

Galtier estudia una serie de casos atestiguados por los historiadores y concluye defendiendo la distinción y consistencia de la "satisfactio secreta) frente a la (professio religiosa). Concede que el término "conversio" tiene dos sentidos en estos escritos de los historiadores por él examinados. Efectivamente el término "conversio» en varias ocasiones designa a aquellos que habían entrado ya 0 , al menos, que habían pedido la entrada en la vida religiosa. Estos constituían, como si dijéramos, la élite de los (conversi». Pero en otras ocasiones, y va estudiando caso por caso para probar su tesis, la expresión (conversi)

16. "Sed hoc de illo dico quem capitalia et mortalia peccata non gravant; nam quae mortalia crimina post baptismum commissa premunt, hortor prius publica poenitentia satisfacere, et ita sacerdotis iudicio reconciliatum communioni sociari, si vult non ad iudicium et condemnationem suí eucharistiam percipere. Sed et secreta satisfactione solvi mortalia crimina non negamus, sed mutato prius saeculari habitu, et confesso religionis studio per vitae correptionem, et iugi imo perpetuo luctu miserante, Deo veniam consequatur: ita duntaxat ut contraria pro his quae poenitet agat et eucharistiam omnibus dominicis diebus supplex ef submissus usque ad mortem percipiat" (GENNADII MASSILIENSIS, De ecclesiasticis dogmatis c. 53, PL. 58, 994).

Se interpretaba en función de un sermón atribuido a Fausto de Riez: S. Fausti Rhẹgiensis sermo II ad monachos, PL. 58, 875-876.

17. P. GALTIER, "Pénitents et convertis. De la pénitence latine a la pénitence celtique": Revue d'Histo're Ecclesiastique 33 (1937) 5-29, 277-305.

18. C. VOGEL, La discipline pénitentielle ei Gaule. Des origines à la fin du vil siècle, Paris 1952, 128-138. 
designa un número más amplio de personas que exteriorizaban su intención de llevar una vida más ordinaria con una forma especial de vestirse, aunque sin llegar a un vestido uniformado.

Era una forma de vida que no llevaba el compromiso de abandonar el mundo y la familia, ni se comprometían a esa vida especial mediante un compromiso escrito. La existencia de estos "conversi) queda atestiguada por varios historiadores que los describen, y por otros muchos que se querellan de que la vida de tales "(conversi)" no responde a la que indican sus vestidos y sus palabras ${ }^{19}$.

Por la misma concepción, pues, de la (professio religiosa) y la descripción que hacen de los "conversi», podemos concluir que se trataba de dos estados o formas distintas de hacer penitencia, a las que acompañaba el perdón de los pecados. La vida religiosa suponía un hábito monacal más o menos determinado, mientras que en cuanto a los "conversi) no había una determinación uniforme de vestido; los religiosos se retiraban del mundo y vivían en soledad o en comunidad, mientras que los (conversi) seguían viviendo en el mundo, entre sus familiares y con sus propias ocupaciones anteriores a su (conversio"; finalmente el religioso se comprometía con Dios mediante un compromiso escrito, mientras que para el (conversus) no existía tal condición.

Estas referencias son suficientes para dar consistencia y vida, propia independiente a cada una de las dos formas de penitencia, aunque ciertamente existían ciertas obligaciones comunes: la vida llevada en castidad y la permanencia en el respectivo estado durante todo el resto de la vida. Los pastores de almas llegarán a preguntarse sobre la conducta a seguir con aquellos que, después de haber abrazado uno u otro estado, eran infieles al mismo.

Tratemos ahora de cimentar la consistencia del estado de los «conversi) frente a los que se encontraban en el (ordo poenitentium). Son varios los concilios que usan la expresión (conversus» 0 "professus». Un cierto número de estos cánones prohibe a los (conversi) o (professi») ser ordenados ${ }^{20}$, mientras que los otros exigen a los candidatos a las

\footnotetext{
19. P. GALTIER, "Pénitents et convertis... etc.": Revue d'Histoire Ecclesiastique 33 (1937) $5-29,277-305$.

S. SALVIANI MASSILIENSIS PRESBYTERI, De gubernatione Del octo libri PL. 53, 77-8, 117, 227 JULIANI POMERII, De vita contemplativa libri tres PL. 59, $448 \mathrm{~A} / \mathrm{B}$.

20. Algunos cánones prohiben ordenarse a los que han practicado la penitencia oficial: "Poenitentiam professi ad clericatum penitus non vocentur" (Concilium Epaonense c. 3, MANSI, 0.c. VIII
} 
órdenes sagradas la práctica anterior de la "conversio" o de la "professio». Es claro, pues, que no se expresa el mismo concepto en ambos grupos de textos. Necesariamente ha de ser distinta la (conversio") o "professio" que se exigía como preparación para recibir las órdenes sagradas, de aquella otra (conversio" o "professio" que impedía el acceso a la clericatura o si era ya clérigo le incapacitaba para practicar la penitencia oficial... Son, pues, dos estados distintos e independientes el uno del otro.

Esta (conversio) se refería a una conversión tardía, lo que explica que existieran o pudieran existir ciertos pecados graves. $Y$ en cuanto a tales pecados existía la convicción -o parece existir- de que tal "conversio" los perdonaba. El texto de Genadio es discutido. Algunos lo aplican a la vida religiosa. Galtier ${ }^{21}$ defiende y cree probar que se refiere a la "conversio») o (satisfactio secreta). Genadio, en el citado texto, no llega a la afirmación clara y decidida de que la (conversio» religiosa borre los pecados. Pero sí que dice (non negamus») que los perdone ${ }^{22}$. Vogel se apoya precisamente en este texto para afirmar que los contemporáneos de $\mathrm{S}$. Cesáreo de Arlés se creían que la "conversio" o "satisfactio secreta) borraba los pecados ${ }^{23}$. Efectivamente Genadio nos hace pensar que en su tiempo existía la convicción de que la "satisfactio secreta") o "conversio" borraba los pecados y Genadio no se atreve a desmentir tal convicción: (nos non negamus».

Pero ni aún estas dos formas solucionaban plena y satisfactoriamente el problema. Mantenían la exigencia de la castidad total durante toda la vida ${ }^{24}$. Muchos aplazaban la exteriorización de su arrepentimiento hasta la hora de la muerte sin comprometerse con ninguna de las tres formas de obtener el perdón hasta ahora indicadas :

-penitencia oficial

- professio religiosa

- satisfactio secreta

\footnotetext{
559) "... ita ut de ipsis quoque, qui ordinandi sunt clerici regulari custodiatur studio, ne aur duarum uxorum vir, aut renuptae maritus, aut poenitentlam professus... ad suprascriptos ordines promoveatur" (Concilium Aurellanense III, c. 6, MANSI 0.c. 13).

Otros concilios, en camblo, exigen que hayan practicado la penitencia: "Assuml allquem ad sacerdotium non posse in coniugii vinculo constitutum, nisi fuerit praemissa conversio" (Concllium Arelatense 11, c. 2, MANSI, o.c. VII, 880); Concilium Epaonense c. 37, MANSI, o.c. VIII, 563; Concillum Arelatense IV, c.1-2, MANSI o.c. 626;

21. P. GALTIER, a. c.

22. vid. nota 16.

23. C. VOGEL, La discipline pénitentielle en Gaule. Des origẹnes a la fin du VII slècle, Paris $1952,133$.

24. C. VOGEL, Le pécheur et la pénitence au Moyen-Age. París 1969, 22-24; vid., notas 14-23.
} 
Esto nos lleva a relatar una cuarta forma de obtener el perdón de los pecados o, al menos, la posibilidad de poder participar en los cultos litúrgicos hasta en la comunión. Es el (agere poenitentiam) como opuesto al (accipere poenitentiam) que se plantea con el discutido caso del modo de proceder con los moribundos.

D La cuestión de los moribundos. "Agere poenitentiam» contrapuesto al (accipere poenitentiam» como forma de obtener el perdón de los pecados o, al menos la disposición suficiente para poder comulgar.

La cuestión de la penitencia (in extremis) ha constituido uno de los problemas fundamentales en la pastoral del siglo VI. Supone una gran mitigación que no dejaba tranquilos a todos. No queremos decir que constituya un problema totalmente nuevo y propio del siglo VI. Unicamente queremos afirmar que la pastoral de este siglo se centra de una forma especial sobre él, de una forma parecida a como en los siglos anteriores se había centrado sobre la conducta a seguir con los adúlteros, los apóstatas y homicidas. Encontramos repetidas intervenciones de los Papas y de algunos concilios locales sobre este tema.

El problema se presentaba así: Por las dificultades que ofrecían tanto la penitencia oficial, como la "professio religiosa) y la (satisfactio secreta), un considerable número de cristianos no practicaba ninguna de las tres formas de obtener el perdón de los pecados y aplazaba la práctica de la penitencia oficial hasta los últimos días de su vida. Así se liberaban del conjunto de obras penosas y consecuencias que llevaba consigo la penitencia oficial. Porque, si bien es cierto que estos moribundos, si revivían, estaban obligados a someterse a la penitencia oficial; también es cierto que la mayor parte moría puesto que, antes de administrarles la penitencia oficial, se procuraba tener la mayor seguridad posible de que moriría. Comprendemos que, siendo esto así, la actitud pastoral para con los enfermos introducía una importante modificación en la práctica de la penitencia oficial. Se suprimía nada menos que el periodo satisfactorio ${ }^{25}$. Y esto se hacía en medio de una mentalidad que concedía a la satisfacción la hegemonía del engra-

25. C. VOGEL, La discipline pénitentielle en Gaule. Des origines a la tin du VII siecle. Paris 1952, 54; iD., "Un problème pastoral au VI siècle. La paenitentia in extremis au temps de Césaire évêque d'Arles": Parole de Dieu et Sacerdoce, Paris-Tournai 1962, 130 , 
naje penitencial. Suprimía las obras satisfactorias pre-penitenciales y también las temibles obligaciones post-penitenciales.

Por tanto la doctrina común ofrecía argumentos claros en que fundamentar una oposición decidida a la administración de la penitencia (in extremis). Y quienes se oponían eran conscientes de que sus argumentos estaban enraizados en la doctrina eclesiástica tradicional hasta entonces.

Cuantas intervenciones encontramos de la Iglesia de Roma se inclinan por la benignidad y defienden la concesión de dicha penitencia $^{26}$. No obstante, a pesar de las claras intervenciones de los Papas podemos decir que, en mayor o menor grado, una buena parte de los pastores de almas - de obispos- fueron víctimas de la angustiosa búsqueda de una solución satisfactoria para todos. Vadeaban entre lo que creían exigencia de los principios y las necesidades concretas de tantos fieles. Hasta los más inclinados por la benignidad debieron experimentar esta inquietud, a pesar de las decididas intervenciones de Roma, hasta encontrar una solución que personalmente los satisficiera. Así nos lo indican la obra y la actuación de $S$. Cesáreo de Arlés ${ }^{27}$.

Unos buscaban la solución en la pregunta y respuesta de Roma. Consultaban a la Sede Romana. No sabemos si éstos quedaban satisfechos con la primera respuesta de Roma a sus inquietudes. Pero sí podemos afirmar que surge una corriente abiertamente opuesta a la concesión de la penitencia (in extremis», basándose en los principios racionales a los que hemos aludido anteriormente: satisfacción prácticamente total de la satisfacción. Piensan que esta corriente está capitaneada por Fausto de Riez ${ }^{28}$. Este hombre ejerció un gran influjo. $Y$ unido al influjo y a la argumentación de Fausto de Riez, los oponentes a

26. Innocentius (1) Exsuperio episcopo Tolosano PL. 20, 498; Epistola Caelestini papae (I) ad episcopos Viennenses et Narbonenses titulorum XI, Tit. III, PL. 56, 577; Leo (I) episcopus Theodo: ro Forojuliensi episcopo c. IV, PL. 1012-3.

27. C.F. ARNOLD, Cäsarius von Arelate und die gallische kirche seiner Zeit, Leipzig 1894; A. MALnORY, S. Césaire, évêque d'Arles, Paris 1894: P. LEJAY. "Le rôle théologique de Césaire évêque d' Arles": Revue d'Histoire et Littérature Religłeuse 10 (1905) 135-188, 217-266, 444 .487, 579-616; E. GóLLER, Studien über das rallische Busswesen zur Zeit Gäsarius von Arles und Gregors von Tours": Archiv für Katholischen Kirchenrecht 109 (1929) 3-126; C. VOGEL, La discipline pénitentielle en Gaule. Des origines à la fin du VII siecle, Paris 1952; C. VOGEL, "Un problème pastoral au VI siècle. La paenitentia in extremis au temps de Césaire évêque d'Arles": Parole de Dieu et Sacerdoce, Paris-Tournai 1962, 125-137.

28. "Utrum incumbentibus extremae angustiis necessitatis, momentanea poenitentia capitales consumere possit offensas? Ipse sibi inimica persuasione mentitur qui maculas longa aetate contractas, subitis et iam inutilibus abolendas gemitibus arbitrarur" (FAUSTO de RIEZ, Epist. 5, CSEL. 21, 184).

Genadio contradice formalmente a Fausto. GENNADII MASSILIENSIS. De ecclesiasticis dogmatibus c. 80 . PL. 58, 998. S. Avit de Veire califica su postura "Adversa veritati et admodum cruda definitio est" (Ep. IV de subitanea poenitentia, éd. Peiper MGH, Auct. Antiq. VI, 2. p. 30). 
la concesión de la penitencia (in extremis) encontraban, al menos en Francia, las decisiones de algunos concilios que negaban la penitencia oficial (in extremis") a ciertos pecados: Así el de Arlés del 3.14 "parece) que se la negaba a los culpables de calumnias y falsas denunciaciones; el de Arlés del 443-452 se la concede a los culpables de estos pecados solamente si habían hecho penitencia durante su vida igualmente que a los apóstatas; igual pensaba el Concilio de Valence de 374 en cuanto a los apóstatas; y a las vírgenes consagradas a Dios - y a su compartes que habían faltado a la castidad solamente los admitía a la penitencia, si durante su vida había practicado una larga penitencia ${ }^{2}$.

Se hacen necesarias repetidas intervenciones de los obispos de Roma para lograr la aceptación del pensamiento benigno. Así Inocencio I interviene en el 405, y Celestino I lo hace en el 422-432, veinte años más tarde, en el mismo sentido. $Y$ las frases empleadas por los Papas revelan un ánimo disgustado, hasta con expresiones duras para aquellos que no siguen la conducta propuesta por la Iglesia de Roma ${ }^{30}$. En el 452 tendrá que intervenir nuevamente el Papa León I ${ }^{31}$. Finalmente es condenada la doctrina de Fausto de Riez y se impone la doctrina benigna. Pero aún entonces vemos que los hombres más sobresalientes por sus preocupaciones pastorales consagran sus mejores esfuerzos a conseguir que los pecadores que dejan la práctica de la penitencia oficial hasta el fin de sus días preparen su eficacia a través de una vida realmente penitencial. La reconciliación (in extremis) no posee una eficacia mecánica e incondicional. Se prepara durante la vida. Y en la medida en que haya sido preparada así dará fruto al final de la vida. Es la fórmula consagrada de $\mathrm{S}$. Cesáreo de Arles: (cagere poenitentiam - penitencia individual, vida penitencial - contrapuesta al "accipere poenitentiam" - práctica de la penitencia oficial. Por eso S. Cesáreo distingue tres clases de pecadores :

a) Los pecadores que llevan una vida pecadora sin escrúpulos, con la esperanza de que la penitencia (in extremis) borrarả todos

29. Concllium Arelatense I c. 14, 22, MANSI o. c. II, 474. Concllium Arelatense II, c. 24, MANSI, o.c. VII, 882; Conclllum Valentinum I, c. 3, MANSI o. c. III, 493.

30. "Agnovimus poenitentiam morientibus denegari, nec illorum desideriis annui qui obitus sul tempore hoc animae suae cupiunt remedium subveniri. Horremus, fratres, tantae Impletatls allquem reperiri, ut de Del pletate desperet; quasi non possit ad se quovis tempore concurrenti succurrere. ot periclitantem sub onere peccatorum hominem, pondere quo se ille expediri desiderat, liberare" (Epstola Coelestini (I) papae ad eplscopos Vlenneses et Narbonenses tltulorum XI, tit. 3 , PL.56, 577).

31. Leo (I) episcopus Theodoro Forojullensi episcopo c. IV, PL. 54, 1012-1013. 
sus pecados. Á éstos el obispo les concederá ciertamente la penitencia oficial, pero no se atreve a garantizarlos el perdón divino.

b) El segundo grupo lo componen aquellos que pecan por ignorancia o debilidad, pero sin esa vana presunción del perdón de los pecados obtenido por la penitencia (in extremis).

c) Finalmente, el tercer grupo está integrado por aquellos que, habiendo pecado, llevan una vida realmente penitencial procurando evitar los pecados posibles de evitar y satisfacer por los ya cometidos.

A estos también les asegurará la obtención del perdón mediante la penitencia final oficial. Más aún también la obtendrán, si, por sorpresa, no pudieran recibir la penitencia ${ }^{32}$.

Esta es la solución que se impone. Se ha llegado así a la que parece solución de compromiso entre los principios de la penitencia canónica y las exigencias pastorales prácticas. En realidad, en cambio, creo que no se trata de un ceder fundamental en el terreno de los prin. cipios. Estos siguen en todo su vigor. Siguen en pie las enormes exi. gencias de la satisfacción por el pecado cometido. No es que las exigencias pastorales no hayan dejado también su fermento y que estén totalmente ausentes en esta solución. Están presentes, pero no pensemos en una imposición de las exigencias pastorales prácticas, en plan de papel dominante, sobre los principios. Unicamente ha sido conseguir una solución positiva : conceder la penitencia (in extremis), mientras que los hombres anclados en la consideración de los principios defendían la solución negativa: no concederla. Pero esta integración de las necesidades pastorales, al lado de las exigencias planteadas por los principios, en la consideración de la decisión final no ha conducido a la negación de los principios, ni siquiera ha negado las exigencias deducidas de los principios. Sencillamente han cambiado, como si dijéramos, su cronología, su orden de ejecución. Según los principios estrictos la práctica penitencial oficial debería comenzarse con la aceptación e incardinación oficial entre los componentes del cordo poenitentium ", a cuya aceptación seguiría un período en el aue el pecador se

32 S. CESAREO, Sermo 60, edic. MORIN p. 252-254; C. VOGEL, "Un probléme pastoral au VI siècle. La paenitentia in extremis au temps de Césaire, évêque d'Arles": Parole de Dieu et Sacerdoce, Paris-Tournai 1962, 125-137; ID., La discipline pénitentielle en Gaule. Des origines a la fin du VII siècle, 79-148; "De caetero autem quod ad paenitentiam spectat, moneatur agere, accipere non cogatur" (S. Avit de VIENNE, Ep. 16 ad Victurium ep., MGH, Auct. Ant' VI, 2, p. 50. 
entregaba a una serie de obras penitenciales, y a continuación la concesión del perdón con las consecuencias post-penitenciales. Mientras que, según la solución de quienes defendían el valor de la penitencia (in extremis), se invertía el orden de las dos primeras etapas entre sí: práctica penitencial durante toda la vida, aceptación como penitente y absolución inmediata sin consecuencias post - penitenciales, puesto que se suponía que moriría en seguida. Se trata, pues, de una simple inversión del orden de las etapas.

Tampoco hemos de olvidar que las intervenciones de Roma son motivadas no solamente por estas corrientes internas existentes dentro de la Iglesia, sino también con su mirada puesta en el novacianismo ${ }^{33}$.

E. La penitencia (tarifada) como nueva forma de adquirir el perdón de los pecados.

Me parece sumamente curiosa la posición de ciertos historiadores, cuando describen la acogida prestada a la penitencia (tarifada) a su llegada al continente. Llama la atención que casi todos limiten la oposición al conocido canon del famoso concilio de Toledo ${ }^{34}$. Y además, tal oposición, viene a decir, no tiene gran importancia porque la Iglesia Española ha profesado siempre un rigorismo desacostumbrado en las demás iglesias occidentales ${ }^{35}$.

Esta actitud la comprendemos en aquellos historiadores que intentan probar la continuidad de la institución sacramental en su forma de penitencia privada ${ }^{36}$. Así Galtier ${ }^{37}$ está tan convencido de que

33. "Ne novatian haeretici negantis veniam asperitatem et duritiam sequi videamur" (INNOCENTIUS exsuperio episcopo. Tolosano, PL: 20; 499).

34. "Quoniam comperimus per quasdam Hispaniarum ecclesias non secundum canonem, sed foedissime pro suis peccatis homines agere paenitentiam, ut quotiescumque peccare voluerint, toties a presbytero se reconciliari expostulent, ideo pro coercenda tam execrabili praesumptione, id a sancto concilio iubetur, ut secundum formam antiquorum canonum detur paenitentia, hoc est, ut prius eum quem sui paenitet facti, a communione suspensum faciat inter reliquos paenitentes ad manus impositionem crebro recurrere; expleto autem satisfactionis tempore, sicuti sacerdotalis contemplatio probaverit, eum communioni restituat: hi vero qui ad propria vitia vel infra paenitentiae tempus vel post reconciliationem relabuntur, secundum priorem canonum severitatem damnentur" (Concilium Toletanum (a. 589) c. XI cit. por A. BOUDINHON, "Sur I'histoire de la pénitence. A propos d'un ouvrage récent": S. Ręviue d' Histoire et Littérature Religieuse 2 (1897) 502).

35. C. VOGEL, La discı́pline pénitentielle en Gaule. Des origines à la fin du VII siècle, Paris 1952,23

36. J. MORINUS, Commentarius historicus de disciplina in administratio sacramenti penitentiae tredecim pnmis saeculis in Ecclesia Occidentall et huc usque in Orientali observata, in decem libros distinctus, Antverpiae 1682; PETAVIO, De poenitentia et reconciliatione veteris Ecciesiae moribus recepta diatriba ex notis in Synesium eruta, 1633; ID, De poenitentia publica et praeparatione ad communionem, 1644; P. BATIFFOL, Etudes d'histoire positive. lere Serie. La discipline de I' arcane. Les origenes de la pénitence, París 1920. 
la penitencia privada ha existido siempre que hasta podría preguntarse, escribe, si no hay testimonios tan antiguos o más sobre la penitencia en su forma privada que sobre la penitencia en su forma oficial antigua o pública como la llaman la mayor parte de los historiadores, aunque no muy acertadamente. $Y$ precisamente uno de los argumentos de los que trata de sacar partido es la no oposición o no extrañeza de que dió prueba el continente a la llegada de la penitencia céltica o (tarifada). Si no ha habido ni oposición ni extrañeza es que con anterioridad ya existía en el continente la penitencia "tarifada) o alguna de sus formas.

Pero no comprendo esta actitud en algunos otros historiadores que

-admiten y defienden la discontinuidad entre la forma antigua de penitencia y la forma (tarifada), negando, al mismo tiempo, que en los primeros siglos existiera forma alguna de penitencia privada o "tarifada")

-y que dan prueba de conocer los concilios franceses y la reforma carolingia ${ }^{38}$.

No encuentro comprensible su postura. Porque efectivamente, la oposición de la Iglesia Española, a través del Concilio de Toledo, es innegable. Pero no es la única ni tampoco podemos decir que haya sido la que más medios ha desplegado en contra de la penitencia (tarifada).

Más bien creo que haya que pensar que cada Iglesia nacional ha reaccionado en el momento exacto en que las circunstancias se lo han permitido. Cuanto mayor era la práctica de la penitencia oficial, y menor el recurso a las formas extraoficiales de penitencia, tanto antes y tanto más fuertemente han reaccionado las iglesias nacionales. En la iglesia española, por unas razones o por otras, parece que en esos siglos aún mantenía cierto vigor la práctica de la penitencia oficial y ello le permite exteriorizarse oficialmente de la manera con que lo hace. En cambio, en la Iglesia Francesa encontramos un alejamiento bastante notable, o casi total, de dicha práctica. Nos hablan de una carencia ca-

37. P. GALTIER, De poenitentla. Tractatus dogmatico-historicus, Roma 1957; ID., L'Eglise ot la rémission des péchés aux premlers slecles, Parls 1932; ID., "Pénitents: Dlctionnaire Apologotique III, Parls 1916, 1846; ID., "Pénitents et convertis": Revue d'Histolre Ecclesiastlque 33 (1937) 5-26, 277-305; ID., Les origines de la pénitence irlandaise": R.S.R. 42 (1954) 58-85, 204-225.

38. Concretamente me reflero a las diversas obras de C. Vogel que hemos citado a lo largo de estas páginas. 
si absoluta de la práctica penitencial ${ }^{39}$. En estas circunstancias no podía esperarse una reacción semejante a la registrada en España. En tales circunstancias la aceptación de la penitencia (tarifada) suponía siempre un avance, aún cuando sus exigencias penitenciales fueran muy inferiores a las de la penitencia antigua.

Los esfuerzos de los monjes irlandeses se encaminan a re-crear el espíritu penitencial en el continente. Van lográndolo poco a poco, aunque no sin oposición. Y dado este primer paso -el renacimiento del espíritu penitencial-, asistimos al despertarse de las exigencias de la Iglesia de Galia de volver a la penitencia oficial en su forma antigua. La expresión más clara de estas exigencias la encontramos en los esfuerzos realizados por los planificadores de la reforma carolingia para restablecer la penitencia antigua. Estos reformadores, reunidos y dirigidos por Chrodegang de Metz, Remigio de Rouen y Alcuino, matizan con su pensamiento una serie de concilios reformadores que se suceden del 8r 3 al $829^{\circ}$.

Los historiadores, que limitan la oposición contra la penitencia tarifada a la Iglesia Española, hacen caso omiso de los cánones de estos concilios, excepto del de Chalon-sur-Saone. Además en su interpretación, intencionadamente dirigida, tratan de probar que la oposición de este Concilio no se refiere directamente a la penitencia (tarifada), como forma de penitencia, sino a los penitenciales y concretamente por los errores que éstos contenían ${ }^{41}$. No negamos que se luche contra la falta de uniformidad y errores contenidos en los penitenciales ${ }^{42}$. Pero el resultado de la contienda nos permite opinar que la lucha va orientada directamente contra la penitencia (tarifada) y que la falta de uniformidad y los errores contenidos en los penitenciales son el argumento y medio de lucha contra ella. De hecho, como escribe Vogel ${ }^{43}$, nada era más ajeno a la penitencia antigua que la penitencia (tarifada). Y

39. M.B. CARRA de VAUX SAINT-CYR. "Le sacrament de pénitence: aperçu historique": Lumière et Vie 13 (1964) 46.

"Vel ob frequentiam hostium externorum vel ob negligentiam praesulum, religionis virtus pene abolita habebatur. Fides tantum manebat, nam paenitentiae medicamenta et mortificationis amor vix vel paucis in illis reperiebatur locis" (JONAS ABBAS ELNONENSIS, Vita S. Columbani abbatis, c. 11, PL. 87, 1017-8) P. BATIFFOL, Etudes de théologie positive... La dlsclpline de l'arcane. Les origines de la pénitence, París 1920, 183-195.

40. C. VOGEL, Le pécheur et la pénitence au Moyen-Age, Paris 1969, 24-25.

41. C. VOGEL, Le pécheur et la pénitence au Moyen-Age, París 1969, 15-16; P. GALTIER, "Les origines de la pénitence irlandaise": R.S.R. 42 (1954) 54-85.

42. "Zur Geschischte der Pönitentialbücher": Archiv für Katholischen Kirchenrecht 30 (1873) 204-227, con abundancia de referencias valiosísimas.

43. C. VOGEL, Le pécheur et la pénitence au Moyen-Age, París, 1969, 24. 
esto lo sabían bien los reformadores carolingios. Nada tiene, pues de extraño que reclamen insistentemente la restauración del orden antiguo y manden quemar los penitenciales". Y cobra tal vigor la lucha que, sintiéndose impotentes por sí mismos para dominarla, acuden y piden ayuda a la autoridad imperial como apoyo para conseguir la restauración de la forma antigua de penitencia ${ }^{45}$. Dicha intención está claramente indicada en varios cánones de los citados concilios. Igualmente se deja traslucir que, en su manera de pensar, la solución perfecta consistía en la restauración total y absoluta de la forma antigua de penitencia con la exclusión total de la (tarifada). Si no lo han hecho, no ha sido porque no lo intentaran, sino porque la fuerza de las circunstancias y el arraigo ya adquirido de la penitencia «tarifada) se lo impidió. Esto fuerza a la reforma carolingia a aceptar una solución de compromiso: a pecado público, penitencia pública; y a pecado oculto, penitencia oculta ${ }^{46}$. No podemos considerar esta solución como el fruto de la mentalidad de la iglesia gala: abierta e inclinada a favorecer la penitencia ((tarifada); sino como el compromiso que obliga a hacer determinadas concesiones para conseguir, de alguna manera, la supervivencia de la forma antigua de penitencia. El mismo Vogel ${ }^{47}$ no tiene inconveniente en calificar esta solución de compromiso con las expresiones de (medio-fracaso" o (fracaso-completo",

44. "Paenitentiam agere iuxta antiquam canonum institutionem in plerisque locis ab usu recessit, et neque reconciliandi, antiqui moris ordo servatur: ut a domini imperatore impetretur adiutorium qualiter si quis publice peccat, publica mulctetur poenitentia et secundum ordinem canonum pro merito suo excommunicetur et reconcilietur" (Concllium Cabilonense II, c. 25, MANSI, o.c. XIV, 98).

"Modus autem poenitentiae peccata sua confitentibus aut per antiquorum canonum institutionem aut per sanctarum scripturarum auctoritatem aut per ecclesiasticam consuetudinem imponi debet, repudiatis ac penitus eliminatis libellis, quos poenitentiales vocant, quorum sunt certi errores, incerti auctores; de quibus recte dici potest: mortificabant animas, quae non moriuntur et vivificabant animas, quae non vivebant" (Concilium Cabllonense II, c. 38, MANSI, 0.c. XIV, 101).

"Quoniam multi sacerdotum partim pro incuria, partim ignorantia modum poenitentiae reatum suum confitentibus secus quam iura canonica decernant, imputent, utentes scilicet quibusdam condicillis contra canonicam auctoritatem scriptis, quos Poenitentiales vocant, et ob id non vulnera peccatorum curant, sed potius foventes palpant etc. Omnibus nobis salubriter in commune visum est, ut unusquisque Episcoporum in sua parochia eosdem erroneos codicillos diligenter perquirat et igni tradat, ne per eos ulterius sacerdotes imperiti homines decipiant" (Concilium Parlsiense VI, c. 32 , MANSI, o.c. 559-560).

45. Cfr. nota 44.

46. "Quod autem supra diximus de his agatur qui publice ad confessionem venerint ot publice poenitentiam egerint. Quod si occulte actum est, et occulte ad sacerdotem venerint, et puram confessionem fecerint, occulte poenitere secundum aetatis modum quod superius continetur... Aduiterium si suis presbyter perpetraverit, sive palatum et publice cognitum, ab ordine sacerdotii cesabit et publica poenitentia decem annorum purgabitur. Quod si occulte hoc fecerit, et occulte ad confessionem venerit, occulte ei poenitentia imponatur" (THEODULFI AURELIANENSIS EPISC., Capitula ad presbyteros Parochlae suae. Theodulfi capitulare ad eosdem, PL. 105, 215 A/D)

47. C. VOGEL, Le pécheur et la pénitence au Moyen-Age, París 1969, 24-27: ID., "U n probleme pastoral au VI siècle. La paenitentia in extremis au temps de Césaire, évêque d'Arles": Parole de Dleu et Sacerdoce, Paris 1962, 128. 
como lo es en realidad, puesto que en los siglos VIII y IX es cuando más florecen los penitenciales ${ }^{48}$. Por otra parte esta interpretación de la actuación carolingia parece ser la única acorde con los datos tanto de la época anterior como con los referentes a la época posterior a los penitenciales. En cuanto a la época anterior, hemos visto la fuerte oposición que encontró la solución benigna de otorgar la penitencia a los moribundos, aunque sin olvidar que también contó la Iglesia $\mathrm{Ga}$ la con fuertes defensores. $Y$ en cuanto a la época posterior a los penitenciales, sería coveniente recordar el pensamiento de Laporte $e^{49}$ que se encarga de defender el Penitencial de S. Colombano contra las acusaciones de rigidez que se le hacen. Defiende que, teniendo en cuenta el ambiente en que se debía aplicar - la Iglesia Gala-, más que constituir un baluarte del rigorismo, es un esfuerzo de mitigación.

Sería largo tratar de relatar las mitigaciones sufridas después por la penitencia "tarifada». Bástenos recordar el tema de las redenciones penitenciales ${ }^{50}$.

Una de las causas más influyentes - no digo la única- en esta evolución ha sido la que pudiéramos expresar como (exigencias pastorales del pueblo").

A la hora de precisar las causas que hayan podido dar origen a este cambio de formas en el continente nos encontramos con dos posibles :

-el cambio social operado con la caída del imperio romano y sus costumbres en beneficio de la venida y de las costumbres de los pueblos llamados bárbaros

- y la situación pastoral surgida en la Iglesia a consecuencia de las conversiones en masa.

No puede negarse un cierto influjo a ninguna de las dos causas. Ambas lo han ejercido realmente. ¿Pero cuál de ellas predomina?

\footnotetext{
48. "Zur Geschichte der Pönitentialbücher": Archiv flir Katholischęn Kirchenrecht 30 (1873) 204-227.

49. J. LAPORTE, Le penitential de saint Colomban, introd, et éd, crit, par..., Paris-Tournai 1958.

50. "Zur Geschichte der Pönitentialbücher": Archiv für Katholischen Kirchęnrent 30 (1873) 204-227.

C. VOGEL, Le pécheur et la pénitence au Moyen-Age, Paris 1969, 28-30; A. BOUDINHON, "Sur l'histoire de la pénitence. A propros d'un ouvrage récent": Revue d'Histoire et Littérature Religleuse 2 (1897) 505, 503-506.
} 
Es difícil decidirse por una de ellas, puesto que ambos acontecimientos encuentran su realización histórica en un tiempo muy próximo, cuando nosotros los contemplamos desde nuestro siglo XX. La conversión del Imperio Romano tiene lugar en la primera mitad del siglo $\mathrm{IV}$, y la invasión de los bárbaros se produce en los comienzos del siglo $V$. Son varios los historiadores que consideran más fundamental e influyente la nueva situación interna de la Iglesia creada por las conversiones en masa, después de la paz constantiniana. Esta manera de pensar se apoya en que los primeros documentos que nos hablan de la pérdida de la práctica de la penitencia antigua, nos vienen precisamente de aquellos lugares en los que más se mantenían todavía las condiciones y circunstancias externas creadas por el Imperio. Pero existe otra razón más poderosa. Es la tensión interna, siempre creciente, que, dentro del mismo seno de la Iglesia, creaba la penitencia oficial antigua, tal como creemos que estaba organizada. Podemos resumirla así: "La disciplina penitencial no podía convenir más que a una sociedad de élite. Se apoyaba sobre una comunidad eclesial poco numerosa, con miembros cuidadosamente escogidos, que consideraban sus promesas bautismales como un compromiso sagrado, cuidadosamente madurado y fielmente guardado, a veces hasta con la pérdida de la vida. Estos fieles, que nada ponían por encima de su fe y de su vida cristiana, estaban en condiciones de comprender que la violación de su compromiso les hacía indignos de permanecer dentro de la sociedad elegida de los santos. Estaban preparados para someterse -con el fin de reconquistar su puesto dentro de la comunidad- a duras y largas pruebas. Pero desde el momento en que la Iglesia deja de ser perseguida, desde el momento en que los pueblos comienzan a entrar en masa en la Iglesia, todo lo que se gana en número de adheridos, se pierde en la calidad de los mismos. Esto hacía necesario contar en mayor escala con la debilidad humana) ${ }^{52}$.

"La paz constantiniana mientras provoca la evolución de la mayor parte de las instituciones eclesiásticas, curiosamente no introduce modificación alguna esencial en la organización penitencial... El proceso penitencial, que conduce al perdón, permanece íntegro en toda su severidad) ${ }^{22}$.

51. M. R. CARRA de VAUX, "Le sacrament de pénitence: Aperçu historique": Lumière et Vie 13 (1964) 8-50.

52. C. VOGEL, Le pécheur et la pénitence dans l'Egl'se Ancienne, Paris 1966, 27. 
Podemos afirmar que no respondía a las exigencias de la comunidad cristiana. ¿Por qué? Ya hemos indicado que todos los elementos constitutivos tenían su influjo en el despego que el pueblo cristiano sentía por la práctica penitencial, ya desde los primeros siglos. Pero sobre todo yo creo que la causa fundamental hemos de ponerla en las exigencias post-penitenciales. Buscando una respuesta vamos a recordarlas :

a) Prohibición de seguir usando del matrimonio. Esto llevaba como consecuencia que, cuando un casado o casada, después de pensarlo mucho, se decidía a engrosar las filas de los penitentesoficiales, debía de contar con el consentimiento de la comparte. La harmonía sexual pesa, y habrá pesado, siempre mucho en la comunidad conyugal. Se disminuía, pues, considerablemente la comunidad conyugal.

Si no habían contraido matrimonio se les aconsejaba y hasta parece que se les prohibía el contraerlo posteriormente.

b) Prohibición de usar las armas. Y esto quiere mantenerse en todo rigor en el momento en que el Imperio se ve obligado a defender sus enormes fronteras y en el momento en que los pueblos bárbaros luchan por su expansión ocupando terrenos antes pertenecientes al Imperio. Al Imperio Romano pertenecían los cristianos que pudiéramos llamar viejos; y de los pueblos bárbaros debían venir las nuevas conversiones.

c) Quedaba prohibido el entregarse a los negocios. Ciertamente hay ganancias honestas, pero el acento se ponía sobre la dificultad de mantenerse limpio en medio de una vida de negocios. Prohibición de intentar procesos $\mathrm{y}$, si fueren totalmente necesarios, debían llevarse ante la jurisdicción eclesiástica.

d) Prohibición de que los clérigos practicaran esta penitencia, y si la habían practicado ya, prohibición de recibir las órdenes sagradas. Más tarde se escogen los clérigos de entre aquellos que habian practicado durante un cierto tiempo la (satisfactio secreta).

e) Por todas estas consecuencias y por el temor a la recaída, ya que no era iterable, se desaconsejaba a los jóvenes recibirla en su juventud. Nos encontramos con pasajes en los que claramente se dice que no se les conceda mientras no haya disminuido el ardor de las pasiones y, concretamente, el de la sexualidad. 
Así, pues, podemos decir que quienes se enrolaban en la práctica de la penitencia oficial constituían una especie de estado distinto dentro de los mismos cristianos.

Este somero recuento nos permite afirmar que la penitencia, en su forma antigua, podría responder a la Iglesia de los primerísimos tiempos, pero que muy pronto comenzó a sentirse el disgusto de la no adaptación a las nuevas circunstancias en que debía vivir la comunidad cristiana. La mayor parte de los pastores de almas han sufrido esa tensión surgida entre las exigencias de la forma antigua de penitencia y las posibilidades que ofrecían los cristianos en su esfuerzo por vivir cristianamente. Ciertamente no respondía a partir del momento en que comenzaron las conversiones en masa. No se adaptaba a las posibilidades de la mayor parte de la comunidad. Si, en línea de principio, concedía a todos un medio de exteriorizar su arrepentimiento, en la práctica se lo negaba a la mayor parte de los cristianos o casi a todos. ¿Para qué podía servir una forma de penitencia que excluía a los casados, a los clérigos, a los militares, a los comerciantes $\mathrm{v}$ a los jóvenes, lo mismo que a los que ya la habían recibido una vez? Era, pues, una penitencia para la élite y excepcional. Acercarse a la penitencia era como aceptar la muerte al mundo en vida. De aquí que cada vez fuera mayor el número de aquellos que la aplazaban hasta el fin de su vida. Cuanto mayor era el número de convertidos, mayor era también la distancia que se abría entre el número de los cristianos bautizados y el número de los que practicaban la penitencia oficial. La forma penitencial antigua se convierte así en una especie de preparación para la muerte. Los pastores de almas se han sentido preocupados por esta dilación, pero curiosamente no los invitan a entrar cuanto antes en las filas de los penitentes oficiales, porque admitían lo razonable de las dificultades que encontraban los cristianos para proceder así. De tal forma que más que decir que los cristianos han ido apartándose de la penitencia oficial, quizás tengamos que decir que iamás se han acercado a ella, excepto a la hora de la muerte. Sencillamente, era una forma apropiada para aquellos que se encuentran a la hora de la muerte y para quienes la renuncia a sus ocupaciones sociales - por agotamiento, edad $\mathrm{u}$ otras razones - les permitiera aceptar una vida tan dura y como de separación del mundo. Los pastores de almas no urgían tampoco demasiado su práctica, porque querían salvar también a todo precio las instituciones venitenciales tal como estaban. Con el 
tiempo fueron haciéndose ciertas concesiones y mitigaciones, pero que siempre respetaban lo intacto de la forma oficial de la penitencia. $Y$ dentro de este ambiente encuadrado entre esos dos límites: no urgir demasiado la práctica de la penitencia oficial y salvar lo fundamental de la misma hemos visto surgir esas otras formas de perdonar los pecados: la (professio religiosa), la "(satisfactio secreta) y el (agere poenitentiam) como opuesta al (accipere poenitentiam). Ya hemos visto que las dos primeras formas - la "professio religiosa) y la (satisfactio secreta) - mitigaban en cierto grado las exigencias de la penitencia oficial, pero no tanto como para apartar la solución apetecida. Permanecían algunas de las exigencias fundamentales de la penitencia oficial. Los monjes debían vivir apartados del mundo, solos o en grupo, en perfecta castidad durante todo el resto de su vida y además sabemos que clérigos y monjes no tenían posibilidad de practicar la penitencia oficial, si la deseaban.

La "conversio o satisfactio secreta) va ofrecía algunas ventaias más. Cierto que debían vivir en castidad durante todo lo restante de su vida, pero podían continuar habitando con sus familias y seguir ocupándose de sus negocios o quehaceres habituales - fueran cuales fueran-, parece que podían considerarse en gracia con participación en la eucaristía y al final de la vida podían recibir la penitencia oficial si lo consideraban conveniente ${ }^{53}$. Ventaja esta última bastante considerable, si tenemos en cuenta que, quienes hubieran reconquistado la gracia mediante la penitencia oficial, ya no podian recibirla al final de su vida por más que la desearan y la necesitaran. No obstante si los tales (conversi) se volvían atrás de su decisión eran considerados algo así como apóstatas.

La primera impresión podría inclinarnos a pensar que la (satisfactio secreta) sería practicada por muchos. Parece que sí que se entregaban bastantes a ella, pero no llegaba a constituir, como si dijéramos, un medio penitencial de masas. No olvidemos que se obligaban a vivir en castidad durante toda la vida y que, si no respondía su vida a lo que indicaban las señales externas de (conversus", eran considerados como apóstatas con todas las consecuencias. Obstáculos suficientemente fuertes como para mantener alejados también de esta forma a una buena parte del pueblo cristiano.

Buena prueba de que estas formas o variaciones penitenciales

53. C. VOGEL. "Un probleme pastoral au VI siècle. La paenitentia in extremis au temps de Césaire, évêque d'Arles": Parole et Sacerdoce, Paris-Tournai 1962, 125-137. 
eran casi tan ineficaces como la forma oficial para solucionar el problema que tenían planteado los pastores de almas, es la larga reflexión, expuesta por $\mathrm{S}$. Cesáreo en su predicación, encaminada a encontrar una solución más viable. Cree haberla encontrado en la distinción entre el (agere poenitentiam) y el (accipere poenitentiam». El (accipere poenitentiam) designaba la práctica oficial de la penitencia según la institución admitida por la jerarquía, mientras que el «agere poenitentiam) se refería a la vida penitencial individual regulada por el propio espíritu de penitencia de cada cual y sin hablar nada de compromiso para toda la vida, ni de vida de castidad ni de compromiso de ningún género con la comunidad, como lo hacían la "professio religiosa) y la "satisfactio secreta)" ${ }^{54}$. Pero hemos de advertir que, por lo que se refiere al "agere poenitentiam», no encontramos en ningún sitio la afirmación de que perdonara los pecados, al menos como reconocido de alguna manera oficialmente por la jerarquía. Sencillamente en $S$. Cesáreo de Arlés la vemos como una preparación para que la penitencia recibida (in extremis") obtenga todo el fruto apetecido.

Esto es lo que hace que "hayamos llegado a una situación ridicula : cada vez más una buena parte de la comunidad vivía al margen de los sacramentos y tal vez en estado sacrílego. Los fieles tenían necesidad de la penitencia, pero no acudian por temor a sus exigencias; y el obispo no osa recibirlos o invitarlos por temor a la recaída). $Y$ desde este momento el ordo poenitentium tiende a reclutarse entre los cristianos más fervorosos, para quienes la práctica de la penitencia más que una necesidad era una devoción. Estos no temen sus austeridades, ni la vida casi monástica a que se comprometen recibiéndola. Se convierte así en una especie de devoción en lugar de ser el gran sacramento de los pecadores. Crea una especie de tercer mundo o de instituto secular.

La penitencia (tarifada) tiene su origen en unas islas en las que - se afirma claramente- jamás ha existido la forma oficial de penitencia que se practicaba en el resto de la Iglesia Occidental ${ }^{55}$. Esto nos hace pensar que su forma se ha ido elaborando en función de las necesidades pastorales que aquellos monjes misioneros descubrían en

54. C. VOGEL, Le pécheur et la pénitence dans I'Eglise Ancienne, Paris 1966, 41-47; ID., "Un problème pastoral, au VI siècle. La paenitentia in extremis au temps de Césaire, évêque d'Aries" Parole de Dieu et Sacerdoce, Paris-Tournai 1962, 128 ss.

55. "Reconciliatia in hac provintia publice statuta non est, quia et publica poenitentia non est" Paenitentiale Theodori 1 l. c. 13, par. 4). 
sus catequizandos y nuevos convertidos. $Y$ ésta es la forma que pasará al continente en un momento en que se experimenta en él un vacío tremendo en torno a la forma oficial. La introducían como una solución al problema pastoral que hacía tiempo planteaban las exigencias de la forma tradicional. Hemos de aceptar que "la penitencia antigua no ha muerto bajo el golpe de los bárbaros, sino que se ha derrumbado por su propio peso" o que "ha sido el mismo triunfo de la cristiandad antigua la que ha conducido a la desaparición progresiva a la penitencia antigua) ${ }^{\text {s. }}$.

Constatamos que en la nueva forma - la (tarifada) - se han ido suprimiendo progresivamente aquellos elementos que hacían impracticable la penitencia antigua. La penitencia (tarifada) en sus comienzos acentúa todavía fuertemente el sentido vindicativo y satisfactorio de las obras penitenciales. Las penitencias, aunque hayan disminuido considerablemente en su rigor, siguen siendo todavía duras. Sería curioso sumar la cantidad de años durante los cuales no pocos tenían que practicar obras penitenciales y mantenerse apartados de la comunidad eclesial o, al menos, de la participación de la eucaristía, puesto que en sus comienzos no se concedía la reconciliación hasta que se hubiera cumplido plenamente la penitencia impuesta. Por esta razón podríamos ir relatando una serie de mitigaciones constatables también en la evolución de la forma (tarifada). Mitigaciones fundamentalmente en torno a las obras penitenciales que con el tiempo admitirán la redención y conmutación de las mismas. Llega también el momento en que se deja al arbitrio del confesor el proporcionar la penitencia a las condiciones personales del penitente -olvidando un poco lo estatuido en los penitenciales-y entre las que también contaba el mayor o menor grado de arrepentimiento manifestado por el penitente. $Y$ en cuanto a la absolución, del aplazarla hasta haber cumplido toda la penitencia, se pasa a concederla a la mitad del cumplimiento de la misma $y$, finalmente, se concede inmediatamente después de haberse comprometido seriamente a cumplirla. Al tomar esta decisión se tenía en cuenta la imposibilidad -en muchos casos- del sacerdote de retornar en el momento en que el penitente hubiera terminado de cumplir su penitencia ${ }^{n}$.

\footnotetext{
56. M. B. CARRA de VAUX, "Le sacrement de pénitence: Aperçu historique": Lumlère et Vie 13 (1964) $38,39$.

57. A. BOUDINHON. "Sur l'histoire de la pénitence. A propos d'un ouvrage récent": Revue d'Histoire et de Litterature Rellgleuse 2 (1897) 503-505.
} 
La misma aceptación de los penitenciales responde a las necesidades pastorales que planteaba la participación activa de tantos sacerdo. tes que hasta ese momento no tenían responsabilidad alguna en la administración del sacramento de la penitencia. El número de ministros del sacramento había aumentado repentinamente. $\mathrm{Su}$ inexperiencia exigía una orientación y uniformidad. Pero estos penitenciales que, en principio, daban orientación y uniformidad, se multiplicaban asombro. samente y se echan de ver divergencias entre ellos en cuanto a la apreciación de las faltas y en cuanto a la penitencia a imponer por una misma falta. Cada uno de ellos exteriorizaba e iba impregnado y exteriorizaba el criterio apreciativo personal de cada una de las escuelas de que procedían. De aquí que los reformadores carolingios, apoyándose en dicha falta de uniformidad y en los errores contenidos en los penitenciales, trataran de volver a la forma antigua. Ya indicamos que no lo consiguieron. Las circunstancias y las raíces echadas ya por la penitencia (tarifada) les forzaron a la solución de compromiso anterior. mente descrita: a pecado público, penitencia pública; y a pecado oculto, penitencia oculta.

Podríamos decir que las circunstancias ambientales modelan ciertos elementos de la práctica penitencial. La Iglesia que, en sus primeros tiempos, había adaptado la forma de exteriorización de la gravedad del pecado a la mentalidad de los hombres del Imperio, más tarde : tratará de adaptarla a la mentalidad del hombre de la invasión. En ambos casos se mantiene en pie el sentido vindicativo y satisfactorio de la penitencia. Pero se exterioriza de forma distinta : en la antigua penitencia duraba cuanto tiempo permanecía formando parte del "ordo poenitentium», mientras que en la penitencia "tarifada) se expresa a través de la "Wertgeld». Una práctica que tan profundamente arraigó que fue necesario, para desterrarla, la intervención de algunos concilios locales ${ }^{58}$. (Es imposible no tratar de relacionar esta penitencia antigua - la exclusión de la comunidad eclesial como élemento fundamental suyo- con los usos romanos, y, en particular, con las penas infligidas a los ciudadanos romanos, entre las cuales la principal era el exilio. Las costumbres de los pueblos bárbaros, y, sobre todo, su código penal, se fundaban en otro espíritu. Entre los bárbaros casi todos los delitos crímenes eran castigados con una compesación o

58. Concilium Cleveshoviae II, c. 26-27, MANSI, o.c. XII, 403-406. 
reparación monetaria, la «Wertgeld». Era, pues, natural que la disciplina judiciaria de la Iglesia fuera modificada en sus usos en conformidad con las costumbres que comenzaban a imponerse con los pueblos invasores, aunque sin alterar nada de lo esencial. Este fue el origen de la penitencia "tarifada" en algunos de sus elementos.

"La exclusión temporal de la Iglesia no podía parecer una pena a los rudos bárbaros a los que los misioneros se esforzaban de arrancar a la idolatría y convertir al Evangelio. Y mucho menos podría habérseles impuesto uniformemente como condición de reconciliación, después de sus pecados, el estado de penitencia, es decir, la prohibición de contraer matrimonio o de usar del ya contraído y la obligación de renunciar a toda función pública, sobre todo la de no llevar armas. Las costumbres de estos pueblos hacían necesarias otras formas, y otro método: lo mismo que, según las leyes de los bárbaros, los culpables debían compensar, según una estimación legal, el mal causado con su falta; así era natural imponerles, según una estimación pareci$\mathrm{da}$, una reparación por la ofensa hecha a Dios con sus pecados. Era la (Wertgeld» aplicada a la vida espiritual» ${ }^{59}$.

\section{ZaCARIAS Herrero}

59. A. BOUDINHON "Sur I'Histoire de la pénitence. A propos d'un ouvrage récent": Revue d'Histoire ef Littérature Religieuse 2 (1897) 496-497. 